\title{
Estrategias de prevención en el paciente con deficiencia auditiva
}

Prevention strategies in the patient with

hearing impairment
Estratégias de prevenção no paciente com deficiência auditiva
Fecha de Recepción

18 de junio 2019
Aceptado para su publicación

02 de julio 2019
Sandra E. Martínez

Alejandro J. Encina Tutuy

Carolina E. Barrios

María Silvina Dho

María Julia López Vallejos

María Agustina Romero

María A. Acosta

Práctica Clínica Preventiva I. Módulos Introducción a la Práctica Preventiva e Introducción a la Práctica Clínica.

\section{Autor de correspondencia}

Sandra E. Martínez

Facultad de Odontología.

Universidad Nacional del Nordeste.

Avenida Libertad 5450 (3400)

Corrientes, Argentina.

Tel: $+5493794457992 / 93$. Cel:

+5493794400703 .

Email:semartinez@odn.unne.edu.ar saelma_67@hotmail.com

\section{Resumen}

El mayor obstáculo en la atención odontológica de personas con deficiencias auditivas se establece por la dificultad en la comunicación. El objetivo del trabajo fue valorar el impacto de una estrategia de prevención implementada en pacientes sordos e hipoacúsicos. La Escuela Especial $\mathrm{N}^{\circ} 9$ para sordos e hipoacúsicos "Helen Keller" de la ciudad de Corrientes, es una institución pública donde asisten 120 alumnos con diferentes capacidades auditivas. A los alumnos se los instruyó en el desarrollo de una correcta técnica de cepillado y se determinaron los Índices Gingival y de placa bacteriana, usando como estrategia para la transmisión de la información, diferentes técnicas de comunicación. Los datos obtenidos fueron procesados utilizando el Programa Infostat. Se evaluaron 60 pacientes, 34 de sexo masculino y 26 de sexo femenino, con una edad promedio de II.2 años. El $84 \%$ de los pacientes presentaron, en el primer control, valores compatibles con salud a nivel gingival ( $\leq$ a I) y el $94 \%$ presentó valores no compatibles con salud en cuanto a la presencia de placa bacteriana en la cavidad bucal ( $\geq$ a $20 \%$ ). En el segundo control, se incrementó el porcentaje de pacientes con grado 0. En el segundo control del índice de placa sólo los que recibieron información por medio de un intérprete demostraron descenso en los valores. En los pacientes sordos y con deficiencias auditivas, no se logra una comunicación efectiva. Es necesaria la presencia 
REVISTA FACULTAD DE ODONTOLOGÍA

ISSN 1668-7280 / ISSN-E 2683-7986

48

de un intérprete, en el marco de las estrategias de prevención.

Palabras claves: Discapacidad, Higiene Oral, Cavidad Bucal.

\section{Abstract}

The greatest obstacle in the dental care of people with hearing deficiencies is due to difficulties in communication. The objective of the study was to assess the impact of a prevention strategy implemented in deaf and hard of hearing patients. Special School No. 9 for deaf and hard of hearing people, called "Helen Keller", located in the city of Corrientes, is a public institution that serves 120 students with different hearing abilities. The students were instructed to develop a proper brushing technique using different communication methods as a strategy for the transmission of information. The Gingival and bacterial plaque indexes were determined. The data obtained were processed using the software Infostat. Sixty patients were evaluated, 34 male and 26 female, with the age of II.2 in average. $84 \%$ of the patients presented, in the first check-up, values compatible with health at the gingival level ( $s \mathrm{a} \mathrm{I}$ ) and $94 \%$ of the patients presented values not compatible with health regarding the presence of bacterial plaque in the oral cavity ( $z$ a twenty\%). In the second check-up, the percentage of patients with grade 0 increased. In the second plaque index check-up, only those who received information through an interpreter showed decrease in the values. In patients with hearing impairments, effective communication is not achieved. The presence of an interpreter is necessary, within the framework of prevention strategies.

\section{Key Words: Disability, Oral Hygiene, Oral Cavity}

\section{Resumo}

O maior obstáculo no atendimento odontológico de pessoas com deficiência auditiva é estabelecido pela dificuldade na comunicação. O objetivo do estudo foi avaliar o impacto de uma estratégia de prevenção implementada em pacientes surdos e com deficiência auditiva. $\bigcirc$ estudo foi feito na Escola Especial $n^{\circ} 9$ para surdos e deficientes auditivos "Helen Keller" da cidade de Corrientes, é uma instituição pública onde frequentam 120 alunos com diferentes habilidades auditivas. Os alunos foram instruídos para o desenvolvimento de uma técnica de escovação adequada. Os índices de placa bacteriana e gengival foram determinados, utilizando diferentes técnicas de comunicação como estratégia para a transmissão da informação. Os dados obtidos foram processados usando o Programa Infostat. Foram avaliados 60 pacientes, sendo 34 do sexo masculino e 26 do sexo feminino, com média de idade de II,2 anos. $84 \%$ dos pacientes apresentaram nos primeiros valores de controle compatíveis com a saúde da gengiva ( $\leq$ I) e $94 \%$ não possuíam valores compatíveis saúde para a presença da placa bacteriana na cavidade oral ( $\geq$ um $20 \%$ ). No segundo controle, a porcentagem de pacientes com grau 0 foi acresentou. No segundo controle do índice de placa somente os que receberam informação através de um intérprete demonstraram descenso nos valores. Em pacientes surdos e com deficiência auditiva, a comunicação efetiva não é alcançada. A presença de um intérprete é necessária, no âmbito das estratégias de prevenção.

Palavras chave: Incapacidade, Higiene Bucal, Cavidade Oral

\section{Introducción}

La sordera es la privación parcial o total de la capacidad de oír'. El término "sordera" se usa en general para describir todos los tipos y grados de pérdida auditiva. Sordera, discapacidad auditiva e hipoacusia se utilizan frecuentemente como sinónimos, para hacer referencia tanto a niveles de pérdida auditiva leves como profundos. No obstante, la mayor parte de las personas que se califican a sí mismas como sordas, aún cuando no puedan oír ni entender el habla, sí pueden expresarse con un lenguaje.

La sordera se clasifica en leve, media, severa y profunda. En la sordera leve, el umbral de la audición se sitúa entre 20 y 40 decibeles (dB), por lo que, en condiciones normales, quienes la padecen, pueden pasar desapercibidos. En 
ambientes con ruido, pueden tener dificultades para comprender los mensajes, más cuando deben reconocer palabras de uso poco frecuente. Perciben el habla de los demás expresadas con voz normal, pero pueden tener dificultades en el habla con voz baja o lejana. En mensajes hablados pueden solicitar repetición porque no llegan a una percepción perfecta de la información.

En la sordera media, el umbral de audición se encuentra entre 41 y $70 \mathrm{~dB}$. Los afectados no perciben bien una conversación normal. Perciben el habla si el interlocutor eleva un poco la voz y lo mira de frente. Se benefician de la lectura labial. Captan algunos ruidos familiares de la vida diaria, otros ya no los detectan o no los identifican.

La sordera severa es aquella cuyo umbral está entre 71 y $90 \mathrm{~dB}$. El proceso de adquisición del lenguaje oral no se realiza de manera espontánea. Requieren un sistema visual de comunicación. No perciben fácilmente la conversación ni los sonidos lejanos, si los ruidos intensos y graves.

La sordera profunda, cuyo umbral está entre 91 y $120 \mathrm{~dB}$, implica problemas para el aprendizaje del lenguaje oral por vía auditiva.

La cofosis es la pérdida total de audición. Por encima de los $120 \mathrm{~dB}$ no hay restos auditivos ${ }^{2}$. La sordera es una de las alteraciones sensoriales más frecuentes en el hombre ${ }^{3}$.

Entre las causas más comunes de su aparición se encuentran: la alteración de la conducción del sonido en el oído interno y la percepción de sonido por las células sensoriales de la cóclea ${ }^{4}$.

El diagnóstico precoz e intervención temprana de la sordera, permite un desarrollo evolutivo, educativo, emocional y comunicativo apropiado ${ }^{3}$.

Del mismo modo que las demás discapacidades, la sordera es analizada desde diferentes perspectivas, de las cuales se destaca el Modelo Social. Este modelo defiende que la concepción de la discapacidad es una 'construcción social impuesta, y plantea una visión de la discapacidad como clase oprimida, con una severa crítica al rol desempeñado por los profesionales y la defensa de una alternativa de carácter político más que científico. Esta posición tiene cierta difusión en algunos medios académicos del Reino Unido y Estados Unidos, y sobre todo en relación con el mundo de la sordera y de la discapacidad física ${ }^{5}$.
De acuerdo al modelo social, las niñas y niños con discapacidad deben tener las mismas oportunidades de desarrollo que aquellos sin discapacidad, basándose en la búsqueda de la inclusión. Las personas con discapacidad son discapacitadas como consecuencia de la negación por parte de la sociedad de acomodar las necesidades individuales y colectivas dentro de la actividad general que supone la vida económica, social y cultural. La discapacidad estaría compuesta por los factores sociales que restringen, limitan o impiden a las personas con diversidad funcional, vivir en una sociedad. En el modelo social la discapacidad se interpreta como el resultado de las barreras sociales ${ }^{6}$.

La presencia de una deficiencia auditiva crea en el paciente una marcada interrupción en su capacidad para comunicarse de manera efectiva, que repercute significativamente en la calidad global de su vida. Esto es atribuido a la reducción de la interacción social, el aislamiento, el sentimiento de exclusión, la depresión, la baja autoestima, $y$ el ser percibido como alguien con la función cognitiva impedida.

Actualmente, el mayor obstáculo en la atención odontológica de personas con deficiencias auditivas se establece en relación con la dificultad de comunicación entre el profesional y el paciente. Este mismo obstáculo es enfrentado en el entorno social y familiar en que vive el individuo. El problema relatado es más evidente en los niños, ya que además de la dificultad en la comunicación por parte del profesional, existen factores de comportamiento de rechazo, normales en el paciente odontopediátrico ${ }^{7}$.

La falta de higiene personal ha sido implicada como uno de los efectos a largo plazo que dificulta la comunicación con los amigos, la familia y los profesionales de la salud ${ }^{8}$.

La comunicación es esencial para poder entender el problema del paciente y sus necesidades. En el caso de problemas de audición, se puede recurrir a materiales escritos, intérpretes y lectura de labios, etc?.

Para el profesional de la salud $y$ en este caso el odontólogo, es importante tener una buena comunicación para recibir toda la información posible acerca del estado de equilibrio físico, mental, social y ambiental del paciente. Existen muchas situaciones en las cuales las alteraciones 
en la cavidad oral pueden afectar la salud general. Ante la necesidad de atender un niño con limitación auditiva, es de vital importancia conocer la etiología y las consecuencias de ésta. Por ello debe informarse acerca de los efectos psicológicos de la deficiencia del niño y la gran dependencia de este con sus padres. Ellos son los primeros intérpretes y de los cuales dependen el comportamiento y conducta ante las actividades de socialización en las diferentes etapas de la vida. La atención odontológica de pacientes con esta limitación, se ve dificultada por los múltiples problemas de comunicación entre odontólogo y paciente. Poseer herramientas y conocimientos por parte de los profesionales de la odontología es necesario para superar la barrera de la comunicación y simultáneamente brindar una atención adecuada a personas con limitación auditiva ${ }^{10}$.

Cuando se trata de estos pacientes, es fundamental establecer medidas de prevención de enfermedades bucales. Autores señalan que, en ellos, el nivel de higiene oral es muy bajo y hay mayor propensión a presentar caries y desarrollar enfermedad periodontal debido a la mala higiene"'.

El cepillado dental es el principal medio mecánico para eliminar la placa bacteriana, ayudando de este modo a prevenir enfermedades bucodentales. Representa la técnica de higiene oral más comúnmente recomendada y utilizada en todo el mundo ${ }^{12,13}$.

En estas condiciones, la posibilidad de intervenir y de fortalecer las decisiones, involucraran un compromiso con la transformación de la salud bucal' ${ }^{14}$.

El objetivo del trabajo fue valorar el impacto de una estrategia de prevención implementada en pacientes sordos e hipoacúsicos.

\section{Metodología}

La Escuela Especial $N^{\circ} 9$ para sordos e hipoacúsicos "Helen Keller" de la ciudad de Corrientes (Argentina), es una institución pública que funciona en un edificio situado en el Barrio Ferré de nuestra ciudad. A la misma, asisten 120 alumnos con diferentes capacidades auditivas, de ambos sexos, con edades entre 6 y 18 años.
Se realizaron actividades de promoción y educación de la salud en la población destinataria, como también, la aplicación de medidas destinadas a la prevención y tratamiento de enfermedades buco-dentales.

A todos los alumnos, se le realizó un examen clínico, informándoles acerca de la importancia del cuidado de la cavidad bucal, se instruyó en el desarrollo de una correcta técnica de cepillado dental y se determinaron los Índices Gingival de Löe y Silness y de placa bacteriana de O'Leary a fin de evaluar el estado gingival y la calidad de higiene oral de cada uno.

Como estrategia para la transmisión de la información, se aplicaron diferentes técnicas de comunicación: utilizando el método de decirmostrar-hacer, combinando el lenguaje oral y la demostración; por medio de un intérprete (familiar o amigo); por un docente de la institución, aplicando el lenguaje de señas y por medio de un audiovisual con apoyo tecnológico, (Figura I).

En la primera visita realizaron el cepillado con su técnica habitual, para ello se les proveyó de cepillo, pasta dental y un espejo de mano. Se realizó la toma de los índices y posteriormente la enseñanza de la técnica de cepillado según la edad.

En la segunda visita, se les solicito que realicen el cepillado dental con la técnica enseñada y se tomaron nuevamente los índices.

Los datos obtenidos en las tomas de los índices se registraron en tablas confeccionadas para tal fin y se efectuaron cálculos de estadísticas descriptivas utilizando el Programa Infostat.

\section{Resultados}

Se evaluaron 60 pacientes, 34 de sexo masculino y 26 de sexo femenino, con una edad promedio de $\mid 1.2$ años.

El $84 \%$ de los pacientes presentaron, en el primer control, valores compatibles con salud a nivel gingival ( $\leq$ a I) y el $94 \%$ presentó valores no compatibles con salud en cuanto a la presencia de placa bacteriana en la cavidad bucal ( $z$ a $20 \%$ ).

En el segundo control, se incrementó el porcentaje de pacientes con grado 0 , reflejando un cambio favorable en el estado gingival, (Tabla I). 

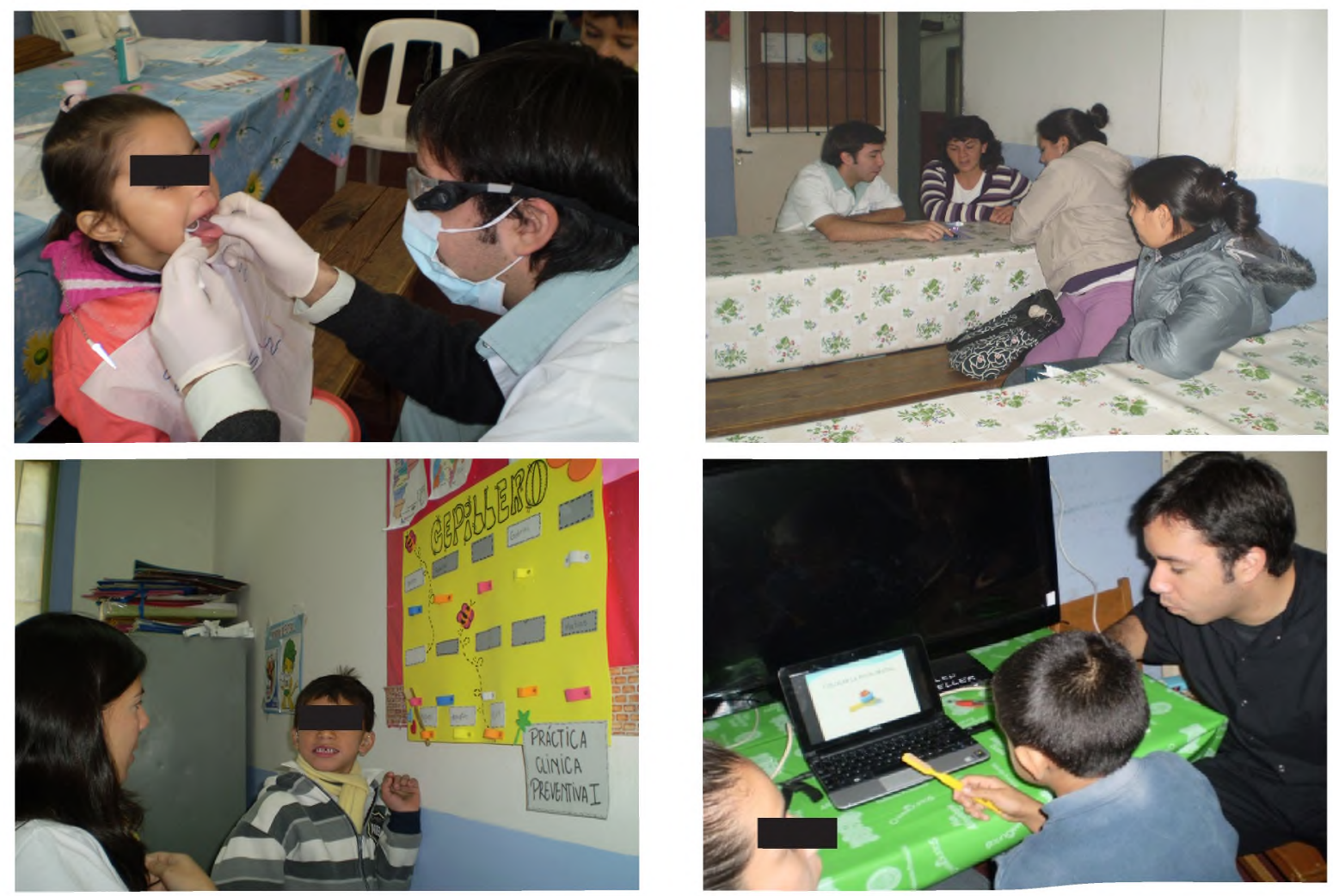

Figura I. Diferentes técnicas de comunicación aplicadas para trasmitir la información

Tabla I. Índice gingival de Löe \& Silness según la estrategia de comunicación aplicada

\begin{tabular}{ccccccccc}
\hline & $\begin{array}{c}\text { Decir-mostrar- } \\
\text { hacer }\end{array}$ & \multicolumn{2}{c}{ Intérprete } & $\begin{array}{c}\text { Lenguaje de } \\
\text { señas }\end{array}$ & Audiovisual \\
\hline Controles & $1^{\circ}$ & $2^{\circ}$ & $1^{\circ}$ & $2^{\circ}$ & $1^{\circ}$ & $2^{\circ}$ & $1^{\circ}$ & $2^{\circ}$ \\
Grado 0 & $86.6 \%$ & $88.9 \%$ & $71.4 \%$ & $100 \%$ & $75 \%$ & $100 \%$ & $91.7 \%$ & $100 \%$ \\
Grado I & $13.4 \%$ & $11.1 \%$ & $28.6 \%$ & $0 \%$ & $25 \%$ & $0 \%$ & $8.3 \%$ & $0 \%$ \\
Grado 2 & $0 \%$ & $0 \%$ & $0 \%$ & $0 \%$ & $0 \%$ & $0 \%$ & $0 \%$ & $0 \%$ \\
\hline Grado 3 & $0 \%$ & $0 \%$ & $0 \%$ & $0 \%$ & $0 \%$ & $0 \%$ & $0 \%$ & $0 \%$ \\
\hline
\end{tabular}


Marúnez - Encina Tutuy - Barrios - Dho - López Vallejos - Romero - Acosta

Tabla II. Índice de placa bacteriana de O’Leary según la estrategia de comunicación aplicada.

\section{Primer control}

\begin{tabular}{lcc}
\hline Decir-mostrar-hacer & $54.3 \% \pm 0.15$ & $56.4 \% \pm 0.19$ \\
\hline Intérprete & $47.7 \% \pm 0.20$ & $26.5 \% \pm 0.10$ \\
\hline Lenguaje de señas & $59.9 \% \pm 0.26$ & $60.2 \% \pm 0.25$ \\
\hline Audiovisual & $43.6 \% \pm 0.22$ & $48.3 \% \pm 0.26$ \\
\hline
\end{tabular}

En el segundo control del índice de placa sólo los que recibieron información por medio de un intérprete demostraron descenso en los valores, (Tabla II).

\section{Conclusiones}

La calidad de higiene oral de la población en estudio es deficiente, haciéndose necesaria la implementación de medidas preventivas tendientes a reducir los factores de riesgo. En los pacientes sordos y con deficiencias auditivas, no se logra una comunicación efectiva.

La educación para la salud adaptada con la presencia de un intérprete, supera la barrera de la comunicación, logrando la satisfacción del paciente.

Un individuo con deficiencias auditivas presenta necesidades especiales de atención, por lo que además requiere de un odontólogo comprometido con su profesión y de la sociedad en su conjunto. 


\section{Referencias Bibliográficas}

I. Lazo, Carmen Marta. Nuevas realidades en la comunicación audiovisual. Tecnos, 2018.

2. Parra LS, Vesga JJ, Trujillo Pinto KV. Actitudes de madres de familia frente a la sordera de sus hijos: caso en un aula básica para sordos. Nodos y Nudos. 2017; 5 (4): I0I115.

3. Borkoski Barreiro SA, Falcón González JC, Bueno Yanes J, Pérez Bermúdez JL, López Cano Z, Ramos Macías Á. Resultados de un programa de detección precoz de la hipoacusia neonatal. Acta Otorrinolaringol [en línea] 20I2; 64(2): 92-6. [Disponible en: http://dx.doi.org//0.1016/j.otorri.2012.07.004]. Fecha de acceso: 10 de mayo de 2019.

4. Zahnert T. The differential diagnosis of hearing loss. Dtsch Arztebl Int. 201I; 108(25):433-44.

5. Tamayo M, Besoaín A, Rebolledo, J. Determinantes sociales de la salud y discapacidad: actualizando el modelo de determinación. Gaceta Sanitaria. 2018; 32(2):96-100.

6. Rodríguez SG. Representación cultural de la discapacidad. PODIUM. 20 I7; 26 (2): I I24.

7. De Conto Möller C, da Silva Ibaldo LT, Ferreira Tovo M. Avaliação das Condições de Saúde Bucal de Escolares Deficientes Auditivos no Município de Porto Alegre, RS, Brasil. Pesq Bras Odontoped Clin Integr. 2010; 10 (2): 195-200.
8. Waldron SK. Auditory sensory impairments and the impact on oral healthcare: $A$ review of the literature. Can J Dent Hygiene. 20| I;45(3): I80-4.

9. Martínez Menchaca HR, Treviño Alanís MG, Rivera Silva G. Guía para el cuidado de la salud oral en pacientes con necesidades de cuidados especiales de salud en México. Rev ADM. 20 I I; 68 (5): 222-28.

10. Ticona NJ. Diagnóstico sobre el conocimiento de salud bucal en escolares del centro educativo "El Altiplano", Yura, Arequipa. Evidencias en Odontología Clínica. 2019; 4 (2): 7-I5.

II. Hernández Martínez CT et al. Manejo odontológico del paciente con hipoacusia neurosensorial profunda bilateral. Revista Cubana de Estomatología. 2017; 54 (3): 0-0.

12. Ahire M, Dani N, Muttha R. Dental health education through the brushing ROBOTUTOR: A new learning experience. J Indian Soc Periodontol. 20I2; 16 (3): 4I7-20.

13. Kumar S, Konde S, Raj S, Agarwal M. Effect of oral health education and fluoridated dentifrices on the oral health status of visually impaired children. Contemp Clin Dent. 20I2; 3 (4): 398-40I.

14. Paiva SM, Álvarez VM, Abanto J. Epidemiología de la caries dental en América Latina. Revista de Odontopediatría Latinoamericana. 20|4; 4 (2): 15-19. 